Discussion Paper No. 711

\title{
ANALYZING THE DECISION TO GET FLU SHOT: AN EMPIRICAL STUDY
}

\author{
Yoshiro Tsutsui, Uri Benzion, \\ Shosh Shahrabani and Gregory Yom Din
}

March 2008

The Institute of Social and Economic Research Osaka University

6-1 Mihogaoka, Ibaraki, Osaka 567-0047, Japan 


\title{
Analyzing the Decision to Get Flu Shot: An Empirical Study
}

January 08, 2008

\author{
Yoshiro Tsutsui $^{1}$, Uri Benzion ${ }^{2}$, Shosh Shahrabani ${ }^{3}$, Gregory Yom Din ${ }^{4}$
}

\begin{abstract}
${ }^{1}$ Yoshiro Tsutsui, PhD, Institute of Social and Economic Research, Osaka University, 6-1 Mihogaoka, Ibaraki, Osaka, 567-0047 JAPAN

${ }^{2}$ Uri Benzion, PhD, Department of Economics, Ben-Gurion University, Beer-Sheva 84105, Israel uriusa@gmail.com and The Economics and Management Department, The Max Stern Academic College of Emek Yezreel, Emek Yezreel 19300, Israel.

${ }^{3}$ Shosh Shahrabani, D.Sc., The Economics and Management Department, The Max Stern Academic College of Emek Yezreel, Emek Yezreel 19300, Israel.shoshs@yvc.ac.il

${ }^{4}$ Gregory Yom Din, PhD, Golan Research Institute, University of Haifa, P.O.B. 97, Katzrin, 12900, Israel,rres102@research.haifa.ac.il
\end{abstract}

Corresponding author: Uri Benzion, Department of Economics, Ben-Gurion University, BeerSheva 84105, Israel uriusa@gmail.com and The Economics and Management Department, The Max Stern Academic College of Emek Yezreel, Emek Yezreel 19300, Israel.Fax:97246423522, Tel: 972-522848321.

\begin{abstract}
Influenza vaccination has been shown to be cost effective in reducing morbidity and mortality and in decreasing work absenteeism and use of health-care resources. The purpose of this study was to identify predictors and beliefs regarding people's vaccination decision against the influenza. It was hypothesized that Health Belief Model (HBM) categories, such as severity of illness, vaccine effectiveness and side effects of the vaccine, affect the decision to get flu shot. In addition, we examined psychological effects, such as time preference, subjective probability of flu, and attitude toward risk. A questionnaire surveys was conducted in the USA, in 2004. The questions included HBM categories and the psychological effects. The results indicate that the main predictors of past immunization against influenza are: the estimated effectiveness of the vaccination, periodic blood test, perceived severity of flu illness, side effects of vaccine (negative effect), having health anxieties, and subjective probability of being infected. Based upon these results, it is recommended to enlarging people's knowledge regarding the influenza illness, its potential risks, and the potential benefits of the vaccine.
\end{abstract}


Key Words: Flu shot, Health Belief Model, Survey

\section{Introduction}

Influenza vaccination has been shown to be cost effective in reducing morbidity and mortality in the older adult population, and in decreasing morbidity, work absenteeism and use of healthcare resources among the working healthy adult population (Bridges et al., 2000; Campbell et al., 1997; Nichol et al., 2003; Lee et al., 2002). Influenza vaccine prevents influenza illness in approximately $70 \%-90 \%$ of healthy adults under the age of 65 years and in 58\% among persons over 60 years of age (Wilde et al., 1999; Bridges et al., 2000; Demicheli et al., 2000; Govaert et al., 1994). Although influenza vaccination levels increased substantially during the 1990s, further improvements in vaccination coverage levels are needed. For example, in 2004, estimated vaccination coverage among adults with high-risk conditions aged 18-49 years and 50-64 years was $26 \%$ and 46\%, respectively, substantially lower than the Healthy People 2000 and Healthy People 2010 objectives of 60\% (CDC, 2006). Vaccination levels (doses distributed/1000 population) for 2003 were 286 in the USA, 230 in Japan, and 344 in Canada (MIV, 2005).

Based on a large national survey in USA, the current study sought to analyze the impact of health, behavioral predictors, and demographic factors on people's vaccination decision against the flu. A 2004 survey of 4,979 people from different states in the USA was used as the data source. The survey questionnaire comprised questions on various subjects, most of them including numerous items, and among them attitudes toward the flu and flu shots. 
In the model, we hypothesized that beliefs, according to the Health Belief Model (HBM) (Rosenstock et al., 1988), such as severity of illness, vaccine effectiveness, and vaccine side effects, as well as other behavioral variables, such as subjective probability of flu, and time preference, would explain the vaccination decision.

The paper is organized as follows: Section 2 reviews the literature, Section 3 describes the survey data, and Section 4 describes the model and the methods. Section 5 presents the major results. Finally, Section 6 summarizes and concludes.

\section{Literature Review}

The current study is based on the Health Belief Model (HBM). The HBM, developed by Rosenstock et al. (1988), is a systematic method to explain and predict preventive health behavior in terms of certain belief patterns. It focuses on the relationship of health behaviors and utilization of health services. The model has been adapted to explore a variety of long- and short-term health behaviors, including vaccinations (Rhodes and Hergenrather, 2003; Hyman et al., 1994; Champion, 1999; Blue and Valley, 2002).

According to the HBM, the acceptance of an influenza vaccine depends on the following groups of predictors: (a) perception of susceptibility to influenza, (b) beliefs about the severity of influenza, (c) perceived benefits of the vaccine in preventing influenza, (d) perceived barriers to accepting a vaccine (such as: inconvenient, 
expensive, unpleasant, and painful), (d) influence by cues to actions, such as recommendation to take the vaccine.

In support of the HBM, it was shown that those individuals who received the influenza vaccine, as opposed to those who did not receive the vaccine, believed more strongly that influenza is a serious illness and that receiving the influenza vaccine would provide them with health benefits (Blue and Valley, 2002; Nexoe et al., 1999). Reasons cited for not receiving influenza vaccine were similar across studies with reference to perceived barriers to the vaccine. Among the reasons were concern about side effects or vaccine safety, perceptions of effectiveness of the vaccine in preventing illness, lack of awareness, and effectiveness in avoiding illness (Chapman and Coups, 1999b; Heimberger, 1995; Nichol, 1997).

Socio-demographic background, economic status, and health status also have an impact on an individual's decision to be vaccinated. In an empirical study conducted in the U.S.A., Wu (2003) found that people with more education, higher incomes, and better insurance coverage are more likely to get flu shots, among various other types of medical preventive treatments. The author also found that individuals with existing health difficulties are more likely to get flu shots. Doebbeling et al. (1997) showed that older individuals, those with higher socioeconomic status, and those employed longer are more likely to get the influenza vaccine. Moreover, enabling factors such as income, health insurance, and physician visits exhibited a strong relationship with influenza vaccination status as well. Shahrabani and Benzion (2006) showed that living in a densely populated household and smoking heavily are also important factors in predicting the decision not to be vaccinated. 
Time preference is another factor that may affect the flu shot decision, since vaccination involves immediate costs and delayed benefits. Time preference is the extent to which decision makers value future outcomes relative to immediate ones. Consequently, people with future-oriented time preferences should be more likely to adopt preventive measures (Shahrabani et al., 2007). Chapman and Coups (1999a) provide some evidence that individuals' time preference patterns can explain preventive health behavior; in particular, monetary time preferences were found to predict whether people took flu shots.

The current study combines HBM categories with other behavioral aspects such as: time preference, the attitude towards risk, and subjective probability of illness, to examine the main factors affecting the decision to get influenza vaccination.

\section{Survey data}

A 2004 survey of 4,979 people from different states in the USA was used as a source of data. One of the authors has been conducting large questionnaire surveys in the USA, which comprised over 100 questions. In the 2004 survey, questions on the attitudes toward the flu and flu shots are included, which is utilized in this paper. Table 1 summarizes the general characteristics of the survey sample. For example, the proportion of women in the sample was about 55\%, the proportion of subjects over 60 years old was $25 \%$, and the proportion of those who received the flu shot in the past was $59 \%$. The percentage of those who took the vaccine was much higher $(78 \%)$ 
among subjects over 60 years old than among subjects under the age of 60 (53\%). In the next section, we consider the data in an analytical framework.

Insert Table 1 about here

\section{The Model}

\subsection{Variables}

The dependent variable (dEXINJ ) was a dichotomous variable equal to one if an individual has had a flu shot in the past, and zero if not. The explanatory variables included three groups: (a) HBM categories including: susceptibility, seriousness, benefits and barriers, (b) other psychological effects like subjective probability, attitude toward risk, time preference and health motivation, and (c) control variables including demographic variables.

The list of variables, their definitions and short description of the survey questions are presented in Table 2. In addition the table shows the formulas and range we used for each variable and specifies the expected effect direction of each variable on the decision to get the vaccine. A detailed explanation for these variables and hypotheses are given in the following section.

Insert Table 2 about here 


\subsection{Method}

We used the OLS regression model to examine the factors affecting past immunization. In doing this, we speculate the following hypotheses, and test them. ${ }^{1}$

Hypothesis 1: People, who perceived higher seriousness or severity of illness (SEVERILL), have higher subjective probability to get the illness (SBJPROB), and have higher scores for the perceived bother to the family when ill (BOTHRILL), will possibly tend to get the vaccine. The variables in this category include:

- SBJPROB - An individual's subjective probability of being infected by influenza:

- Seriousness of illness- including: SEVERILL - perceived severity of influenza illness, and BOTHRILL - bother to family and friends in case of illness.

Hypothesis 2: People who think benefit from flu vaccination is larger have higher tendency to be vaccinated. As for the benefit from vaccination, we adopt: EFFECT Effectiveness of vaccination: we expect that higher scores for effectiveness of vaccination will positively affect the decision to get the vaccine.

Hypothesis 3: Barriers to accepting a vaccine: people who have higher levels of barriers tend not to take the vaccine. Barriers include MNYCOST - the perceived

\footnotetext{
${ }^{1}$ Hypotheses 1-4 essentially follows the idea of HBM.
} 
cost of flu shot, and SIDEEFF -estimated side effects of flu shot. People who have higher scores costs and higher levels of side effects, may tend not to take the vaccine.

Hypothesis 4: According to the susceptibility item of HBM, we expect that those with higher levels of anxieties about their health will be more highly motivated to take the vaccine. The variable that indicates susceptibility is: HEALTH - Have anxieties about health.

Hypothesis 5: Those who have higher time discount rate (present -orientation) have less tendency to get the vaccine, because they discount future benefits of vaccination more and compare them with the immediate costs of vaccination. ${ }^{2}$ The variable that indicates time preference is TDR - (Referring to the question: "want to postpone pleasure for later"): we expect that a present-oriented attitude will negatively affect the tendency to get the vaccine.

Hypothesis 6: People who are more risk averse are more likely to take the vaccine. The variable that indicates the risk attitude is: RAIN - Referring to the question: "How high does must probability of rain be for you to take an umbrella?" The lower value may represent the people’s risk aversion. We expect that individuals with higher reversed score (lower threshold probability for taking the umbrella) will also have higher incentive to get the vaccine.

Hypothesis 7: People who have higher levels of health motivation will tend to take the vaccine. The variable that indicates health motivation is: dBLDTSTP - Periodic

\footnotetext{
${ }^{2}$ Chapman and Coups (1999a) provide some evidence that time preference patterns can explain preventive health behavior;
} 
blood test. Some evidence indicates that preventive behaviors may be highly correlated with one another (Fukunaga et al., 1997); therefore, we expect that those who took periodic blood tests will have a higher probability of taking the vaccine.

- Control variables: dGENDER- gender; AGE-age; dMARIT -marital status; EDUC-education level, dEXILL- Whether infected by influenza during the last two years. dBLDTSTS - Blood test following suspicion of illness, which may indicate individuals in a risk group.

We estimated the OLS regression for the following equation:

(1) dEXINJ = (dEXILL, SBJPROB, SEVERILL, dBLDTSTP, dBLDTSTS, HEALTH, EFFECT, SIDEEFF, MNYCOST, BOTHRILL, TDR, RAIN, dGENDER, dMARIT , EDUC, AGE)

Table 3 summarizes the mean values of the explanatory variables. The data show that the mean values of the variables, perceived effectiveness of vaccination, and degree of anxiety about health are higher for the group that received the vaccine in the past than for those that never received it, while the mean value of the variable of estimated side effects of the flu shot is higher for the second group.

Insert Table 3 about here

\section{Results}


Table 4 summarizes the results for the OLS model. The results indicate that the main predictors (based on higher scores) of past immunization against influenza are: the estimated effectiveness of the vaccination, and periodic blood test. This means that individuals who perceived the vaccine as relatively effective tend to get the vaccine. In addition, individuals who executed periodic bloods, which indicates higher levels of health motivation, also tend to take the vaccine. These results confirm hypotheses 2 and 7.

We also found that, individual who perceived higher levels of severity of illness, lower levels of perceived side effects, higher levels of health anxieties and higher levels of subjective probability of being infected, received the flu vaccination in the past. These findings confirm hypothesis 4 , which refers to the perceived susceptibility (higher scores of health anxieties), and confirm hypothesis 1 regarding the severity of illness (except for the variable of perceived bother to the family when ill). Yet, the results in table 4 are not compatible with hypotheses 5 and 6, which refer to time preference and attitude toward risk.

The significant control variables affecting the decision to be vaccinated were: age, education, and blood tests (because of suspicion of disease). Older individuals with higher levels of education that executed blood tests (which may indicate individuals in a risk group) took the vaccine in the past.

Insert Table 4 about here 


\section{Summary and Conclusions}

Influenza vaccination has been shown to be cost effective in reducing morbidity and mortality and in decreasing work absenteeism and use of health-care resources. Although influenza vaccination levels have increased substantially during the 1990s, further improvements in vaccination coverage levels are needed.

The current study was conducted to identify the behaviors and beliefs regarding the decision to get the flu shot. It was hypothesized that subjective factors affect the decision of individuals to be vaccinated.

The main results of the study show that individuals who received the vaccine, as opposed to those who did not received it had stronger beliefs that (a) influenza is a serious illness, (b) the vaccine is effective, and (c) there are minor side effects to the vaccine. These results are compatible with the HBM results. Other researchers have also found influenza vaccine acceptance to be influenced by perceptions of effectiveness of the vaccine in preventing illness, and likelihood of vaccine side effects, (Chapman, 1999; Fiebach and Viscoli, 1991; Heimberger, 1995; Nichol, 1997; Blue and Valley, 2002). In addition, we found that individuals who received the vaccine have more anxieties about their health, have higher subjective probabilities to be infected, and have more precautionary motivation. The study adds to the existing literature by combining behavioral factors of the HBM with psychological effects, such as subjective probability of illness. 
Our conclusion from this study is that subjective probabilities, in addition to behavioral factors may affect the decision to get the vaccine. Although this decision has direct effect on the individual itself, it has also direct and indirect effects on the society since influenza is an epidemic disease. Based upon these results, we recommend enlarging people’s knowledge regarding the influenza illness, its potential risks, and the potential benefits of the vaccine. 


\section{References}

1. Blue CL and Valley JM. Predictors of influenza vaccine: Acceptance among healthy adult workers. AAOHN Journal 2002; 50(5); 227-235.

2. Bridges CB, Thompson WW, Meltzer MI, et al. Effectiveness and cost-benefit of influenza vaccination of healthy working adults: A randomized controlled trial. The Journal of the American Medical Association 2000; 284(13); 16551663.

3. Campbell DS, Run-dey MH. Cost-effectiveness of the influenza vaccine in a healthy, working-age population. Journal of Occupational \& Environmental Medicine 1997; 39(5); 408-414.

4. CDC, 2006. Prevention and Control of Influenza Recommendations of the Advisory Committee on Immunization Practices (ACIP). United States Department of Health and Human Services. Centers for Disease Control and Prevention (CDC). available: http://www.cdc.gov/

5. Champion VL. Revised susceptibility, benefits, and barriers scale for mammography screening. Research in Nursing \& Health 1999; 22(4); 341-348.

6. Chapman GB, Coups EJ. Time preferences and Preventive Health Behavior: Acceptance of the Influenza Vaccine. Medical Decision Making 1999a; 19(3); 307-314.

7. Chapman GB, Coups EJ. Predictors of influenza vaccine acceptance among healthy adults. Preventive Medicine 1999b; 29(4); 249-62.

8. Demicheli V, Jefferson T, Rivetti D, Deeks J. Prevention and early treatment of influenza in healthy adults. Vaccine 2000; 18; 957-1030. 
9. Doebbeling BN, Edmond MB, Davis CS, Woodin JR, \& Zeitler RR. Influenza vaccination of health care workers: Evaluation of factors that are important in acceptance. Preventive Medicine 1997; 26(1); 68-77.

10. Fiebach NH, Viscoli CM. Patient acceptance of influenza vaccination. American Journal of Medicine 1991; 91(4); 393-400.

11. Fukunaga I, Jitsunari F, Takeda N, Asakawa F, Maruyama Y. A study of health behavior of the elderly - correlation between participation in health examinations and health behavior. Japanese Journal of Hygiene 1997; 52(2); 490-503.

12. Govaert TM, Thijs CT, Masurel N, Sprenger MJ, Dinant GJ, Knottnerus JA. Efficacy of influenza vaccination in elderly individuals: a randomized doubleblind placebo-controlled trial. The Journal of the American Medical Association 1994; 272(21); 1661-1665.

13. Heimberger T, Chang HG, Shaikh M, Crotty L, Morse D, \& Birkhead G. Knowledge and attitudes of healthcare workers about influenza: Why are they not getting vaccinated? Infection Control and Hospital Epidemiology 1995; 16(7); 412-415.

14. Hyman RB, Baker S, Ephraim R, Moadel A, and Philip J. Health belief model variables as predictors of screening mammography utilization. Journal of Behavioral Medicine 1994; 17; 391-406.

15. Lee PY, Matchar DB, Clements DA, Huber J, Hamilton JD, Peterson ED. Economic analysis of influenza vaccination and antiviral treatment for healthy working adults. Annals of Internal Medicine 2002; 137(4); 225-31. 
16. MIV - Macroepidemiology of Influenza Vaccination study group. The macroepidemiology of influenza vaccination in 56 countries, 1997-2003. Vaccine 2005; 23(44); 5133-5143.

17. Nexoe J, Kragstrup J, Sogaard J. Decision on influenza vaccination among the elderly: A questionnaire study based on the Health Belief Model and the Multidimensional Locus of Control Theory. Scandinavian Journal of Primary Health Care 1999; 17(2); 105-110.

18. Nichol KL, Hauge M. Influenza vaccination of healthcare workers. Infection Control and Hospital Epidemiology 1997; 18; 189-94.

19. Nichol KL, Mallon KP, Mendelman PM. Cost benefit of influenza vaccination in healthy, working adults: an economic analysis based on the results of a clinical trial of trivalent live attenuated influenza virus vaccine. Vaccine 2003; 21(17-18); 2207-17.

20. Rhodes SD, Hergenrather KC. Using an Integrated Approach to Understand Vaccination Behavior Among Young Men Who Have Sex with Men: Stages of Change, the Health Belief Model, and Self-Efficacy. Journal of Community Health 2003; 28(5); 347-362.

21. Rosenstock LM, Strecher VJ, \& Becker MH. Social learning theory and the Health Belief Model. Health Education Quarterly 1988; 15(2); 175-183.

22. Shahrabani S, and Benzion U. The Effects of Socio-Economic Factors on the Decision to be Vaccinated: The Case of Flu-shot Vaccination, The Israel Medical Association Journal 2006; 8; 1-5.

23. Shahrabani S, Gafni A, and Benzion U. Low Flu Shot Rates Puzzle - Some Plausible Behavioral Explanations, The American Economist 2008, forthcoming. 
24. Wilde JA, McMillan JA, Serwint J, Butta J, O'Riordan MA, Steinhoff MC. Effectiveness of influenza vaccine in health care professionals: a randomized trial. The Journal of the American Medical Association 1999; 281(10); 908913.

25. Wu Stephen. Sickness and preventive medical behavior. Journal of Health Economics 2003; 22; 675-689. 


\section{$\underline{\text { Tables }}$}

Table 1. General characteristics of the survey sample

\begin{tabular}{|c|c|c|c|c|c|c|c|c|}
\hline & \multirow[t]{2}{*}{ men } & \multirow[t]{2}{*}{ women } & \multirow[t]{2}{*}{$\begin{array}{l}\text { age }> \\
60\end{array}$} & \multirow[t]{2}{*}{$\begin{array}{l}\text { age }<= \\
60\end{array}$} & \multicolumn{2}{|c|}{ received flu shot } & \multicolumn{2}{|c|}{$\begin{array}{l}\text { infected by flu } \\
\text { during } \\
\text { the last two years }\end{array}$} \\
\hline & & & & & never & ever & never & ever \\
\hline men & 2,231 & & 498 & 1,541 & 920 & 1,311 & 1,809 & 422 \\
\hline women & & 2,748 & 661 & 1,965 & 1,119 & 1,629 & 2,195 & 553 \\
\hline age $>60$ & & & 1,159 & & 251 & 908 & 1,047 & 112 \\
\hline age $<=$ & & & & 3,506 & 1,646 & 1,860 & 2,704 & 802 \\
\hline \multicolumn{9}{|l|}{60} \\
\hline \multicolumn{9}{|c|}{ received flu shot } \\
\hline never & & & & & 2,039 & & 1,604 & 435 \\
\hline ever & & & & & & 2,940 & 2,400 & 540 \\
\hline \multicolumn{9}{|c|}{ infected by flu during the last two years } \\
\hline never & & & & & & & 4,004 & \\
\hline ever & & & & & & & & 975 \\
\hline
\end{tabular}


Table 2. Codes and explanation of the variables, linkage to the questionnaire

\begin{tabular}{|c|c|c|c|c|}
\hline Code & Explanation & Question & Formula, range & direction \\
\hline SBJPROB & subjective probability of illness & Q50 Estimate your chance to be infected by flu during the next 12 months. & Q50, 0 to 100 & increase \\
\hline SEVERILL & severity of illness & Q44 How serious a disease do you think the flu is? & 7-Q44, 1 to 6 & increase \\
\hline BOTHRILL & bother to your family when ill & Q47 When infected, to what extent do you bother your family and friends? & 5-Q47, 1 to 4 & increase \\
\hline dEXINJ & ever received a flu shot & Q41 Have you ever received (1) a flu shot? & No - 0 , yes - 1 & increase \\
\hline dEXILL & infected during the last 2 years & Q43 Have you been infected (1) by the flu during the last two years? & No - 0 , yes - 1 & increase \\
\hline EFFECT & effectiveness of vaccination & Q49 How effective do you think the flu shot is? & 6-Q49, 1 to 5 & increase \\
\hline MNYCOST & cost of flu shot & Q45 How much do you think a flu shot costs? & Q45, 0 to $50,000 \$$ & increase \\
\hline SIDEEFF & side effect of the vaccine & Q46 How serious do you think the side effects caused by a flu shot are? & 8-Q46, 1 to 7 & increase \\
\hline dBLDTSTP & periodic blood test & Q51 Undergo blood test in the last 12 months as part of a periodic test & No - 0 , yes - 1 & increase \\
\hline dBLDTSTS & blood test because of suspicion & Q51 Undergo blood test in the last 12 months because of suspicion of disease & No - 0 , yes - 1 & increase \\
\hline RAIN & threshold for action & $\begin{array}{l}\text { Q21 How high does the probability of rain have to be in order for you to take } \\
\text { an umbrella? }\end{array}$ & $100-\mathrm{Q} 21,0$ to 100 & decrease \\
\hline TDR & time preference & Q2.5 I want to postpone joys for later & 6-Q2.5, 1 to 5 & decrease \\
\hline OVERCON & overconfidence & Q2.6 I will never be robbed & 6-Q2.6, 1 to 5 & increase* \\
\hline HEALTH & have anxieties about health & Q2.12 I have anxieties about my health & 6-Q2.12, 1 to 5 & increase \\
\hline AGE & age & Q57.1 Your birth year? & Q57.1, 1900 to 1990 & increase \\
\hline dGENDER & gender & Q54 & 0 - male, 1 - female & \\
\hline dMARIT & marital status & Q55 & 1 - married, 0 - other & \\
\hline EDUC & education level & Q58.1 The highest level of education completed 1 to 9 & Q58.1, 1 to 9 & \\
\hline
\end{tabular}

* increase effect of the independent variable overconfidence on the subjective probability of individual to get flu shot. 
Table 3. Mean values of the variables

\begin{tabular}{|c|c|c|c|c|c|c|}
\hline & \multirow[t]{2}{*}{ Scale } & \multirow{2}{*}{$\begin{array}{l}\text { Whole } \\
\text { sample }\end{array}$} & \multicolumn{2}{|c|}{ Received vaccination in the past } & \multicolumn{2}{|c|}{ Never received vaccination in the past } \\
\hline & & & Age less than 60 & Age 60 and above & Age less than 60 & Age 60 and above \\
\hline \multirow[t]{2}{*}{ Subjective probability } & $0-100$ & 26.01 & 28.99 & 19.20 & 26.82 & 23.10 \\
\hline & & $(0.35)$ & $(0.58)$ & $(0.73)$ & $(0.61)$ & $(1.58)$ \\
\hline \multirow[t]{2}{*}{ Severity of illness } & $1-6$ & 4.22 & 4.35 & 4.81 & 3.81 & 4.09 \\
\hline & & $(0.02)$ & $(0.03)$ & $(0.04)$ & $(0.03)$ & $(0.09)$ \\
\hline \multirow[t]{2}{*}{ Bother to family when ill } & $1-4$ & 1.68 & 1.73 & 1.53 & 1.73 & 1.57 \\
\hline & & $(0.01)$ & $(0.01)$ & $(0.02)$ & $(0.02)$ & $(0.04)$ \\
\hline \multirow[t]{2}{*}{ Infected during the last 2 years } & (no=0, & 0.19 & 0.22 & 0.09 & 0.23 & 0.11 \\
\hline & yes $=1$ ) & $(0.00)$ & $(0.01)$ & $(0.01)$ & $(0.01)$ & $(0.02)$ \\
\hline \multirow[t]{2}{*}{ Vaccination effectiveness } & $1-5$ & 3.00 & 3.11 & 3.27 & 2.77 & 2.69 \\
\hline & & $(0.01)$ & $(0.01)$ & $(0.02)$ & $(0.01)$ & $(0.05)$ \\
\hline \multirow[t]{2}{*}{ Cost of flu shot } & $0-50000$ & 3.38 & 3.50 & 3.23 & 3.42 & 3.16 \\
\hline & & $(0.02)$ & $(0.03)$ & $(0.04)$ & $(0.03)$ & $(0.09)$ \\
\hline \multirow[t]{2}{*}{ Side effects } & $1-7$ & 3.15 & 2.97 & 2.90 & 3.39 & 3.80 \\
\hline & & $(0.02)$ & $(0.03)$ & $(0.05)$ & $(0.03)$ & $(0.11)$ \\
\hline \multirow{2}{*}{$\begin{array}{l}\text { Periodic blood } \\
\text { test }\end{array}$} & (no=0, & 0.59 & 0.61 & 0.83 & 0.45 & 0.57 \\
\hline & yes $=1$ ) & $(0.00)$ & $(0.01)$ & $(0.01)$ & $(0.01)$ & $(0.03)$ \\
\hline \multirow{6}{*}{$\begin{array}{l}\text { Blood test } \\
\text { (suspicion of illness) } \\
\text { precautionary motivation- } \\
\text { Taking an umbrella Probability } \\
\text { Time preference }\end{array}$} & (no=0, & 0.04 & 0.05 & 0.04 & 0.03 & 0.03 \\
\hline & yes $=1$ ) & $(0.00)$ & $(0.00)$ & $(0.00)$ & $(0.00)$ & $(0.01)$ \\
\hline & $0-100$ & 40.66 & 39.63 & 43.67 & 39.73 & 39.69 \\
\hline & & $(0.42)$ & $(0.67)$ & $(0.94)$ & $(0.77)$ & $(1.89)$ \\
\hline & $1-5$ & 3.18 & 3.16 & 3.28 & 3.17 & 3.17 \\
\hline & & $(0.02)$ & $(0.03)$ & $(0.04)$ & $(0.03)$ & $(0.09)$ \\
\hline \multirow[t]{2}{*}{ Overconfidence } & $1-5$ & 2.60 & 2.56 & 2.61 & 2.61 & 2.54 \\
\hline & & $(0.01)$ & $(0.02)$ & $(0.04)$ & $(0.02)$ & $(0.07)$ \\
\hline \multirow[t]{2}{*}{ Anxieties about health } & $1-5$ & 2.94 & 3.04 & 3.12 & 2.78 & 2.70 \\
\hline & & $(0.01)$ & $(0.02)$ & $(0.04)$ & $(0.03)$ & $(0.08)$ \\
\hline \multirow[t]{2}{*}{ Marital status } & (not mar. $=0$ mar. $=1$ ) & 0.58 & 0.65 & 0.60 & 0.57 & 0.62 \\
\hline & & $(0.00)$ & $(0.01)$ & $(0.01)$ & $(0.01)$ & $(0.03)$ \\
\hline \multirow[t]{2}{*}{ Age } & $0-90$ & 47.61 & 42.25 & 71.56 & 37.97 & 68.74 \\
\hline & & $(0.25)$ & $(0.27)$ & $(0.26)$ & $(0.28)$ & $(0.41)$ \\
\hline \multirow[t]{2}{*}{ Education level } & $1-9$ & 4.80 & 5.02 & 4.62 & 4.75 & 4.46 \\
\hline & & $(0.02)$ & $(0.04)$ & $(0.06)$ & $(0.04)$ & $(0.11)$ \\
\hline
\end{tabular}


Table 4. Results of OLS regression model: Dependent variable received or not flu shot in the past ( dEXINJ)

\begin{tabular}{|c|c|c|c|}
\hline $\begin{array}{c}\text { Explanatory } \\
\text { variables } \\
\end{array}$ & & Coeff. & t test \\
\hline (Constant) & & $-.356^{*}$ & -6.897 \\
\hline SBJPROB & Subjective probability & $.001^{*}$ & 1.901 \\
\hline SEVERILL & Severity of illness & $.049^{*}$ & 10.410 \\
\hline BOTHRILL & Bother family when ill & -.005 & -.625 \\
\hline dEXILL & Infected during the last 2 yrs $($ no $=0, y e s=1)$ & $.028^{\star \star}$ & 1.671 \\
\hline EFFECT & Vaccination effectiveness & $.109^{\star}$ & 12.924 \\
\hline MNYCOST & Cost of flu shot & $.009^{\star}$ & 1.910 \\
\hline SIDEEFF & Side effects & $-.044^{*}$ & -10.956 \\
\hline dBLDTSTP & $\begin{array}{l}\text { Periodic blood } \\
\text { test (no=0,yes }=1)\end{array}$ & $.133^{*}$ & 9.451 \\
\hline dBLDTSTS & Blood test (suspicion of illness) $(\mathrm{no}=0, \mathrm{yes}=1)$ & $.139^{*}$ & 4.286 \\
\hline RAIN & Uncertainty attitude & .000 & .323 \\
\hline TDR & Time preference & .000 & -.042 \\
\hline HEALTH & Anxieties about health & $.028^{*}$ & 5.208 \\
\hline dGENDER & Gender $(\mathbf{0}=\mathbf{M}, \mathbf{1}=\mathrm{F})$ & -.014 & -1.083 \\
\hline dMARIT & $\begin{array}{l}\text { Marital status } \\
(\text { not mar. }=0 \text { mar. }=1)\end{array}$ & .018 & 1.354 \\
\hline AGE & Age & $.006^{*}$ & 13.760 \\
\hline EDUC & Education & $.012^{*}$ & 3.492 \\
\hline R square & & .192 & \\
\hline Adj. R square & & .190 & \\
\hline $\mathbf{N}$ & & 4,979 & \\
\hline${ }^{*}$ p-value $<0.05$ & $* *$ for $\mathrm{p}$-value $<0.1$ & & \\
\hline
\end{tabular}

